\title{
A simulation-based method to compare the pest suppression potential of predators: A case study with spiders
}

\author{
Jacinto Benhadi-Marín ${ }^{\mathrm{a}, \mathrm{b}, *}$, José Alberto Pereira ${ }^{\mathrm{a}}$, David Barreales ${ }^{\mathrm{a}}$, José Paulo Sousa ${ }^{\mathrm{b}}$, \\ Sónia A.P. Santos ${ }^{\mathrm{c}, \mathrm{d}}$ \\ ${ }^{a}$ Centro de Investigação de Montanha (CIMO), ESA, Instituto Politécnico de Bragança, Campus de Santa Apolónia, 5300-253 Bragança, Portugal \\ ${ }^{\mathrm{b}}$ Centre for Functional Ecology, Department of Life Sciences, University of Coimbra, Calçada Martim de Freitas, 3000-456 Coimbra, Portugal \\ ${ }^{c}$ CIQuiBio, Barreiro School of Technology, Polytechnic Institute of Setúbal, Rua Américo da Silva Marinho, 2839-001 Lavradio, Portugal \\ d LEAF, Instituto Superior de Agronomia, Tapada da Ajuda, 1349-017 Lisboa, Portugal
}

\section{A R T I C L E I N F O}

\section{Keywords:}

Biological control

Ceratitis capitata

Functional response

Prey

R library

Spiders

\begin{abstract}
A B S T R A C T
Assessing and comparing the pest killing capacity of predators is a crucial but laborious task during the implementation of sustainable farming systems. Critical attributes of assessment include quantifying predator's attack rate (a) and handling time $\left(\mathrm{T}_{\mathrm{h}}\right)$. The maximum attack rate $\left(\mathrm{T} / \mathrm{T}_{\mathrm{h}}\right)$ (i.e. the maximum number of prey that can be attacked by a predator during the time interval $(\mathrm{T})$ considered) could be a more precise and interpretable indicator of the potential suppression of pests exerted by a predator; however, its calculation only provides a point estimator usually derived from incomplete datasets (e.g. unbalanced or low replicated experimental designs) that could lead to draw wrong conclusions. We introduce simaR (simulation of maximum attack rates using R), an R library that generates $95 \%$ confidence intervals around estimates of the maximum attack rate that can be easily and intuitively used to compare across species. We validated the simulation method and used the empirical results of a controlled laboratory experiment to compare the maximum attack rates of spiders across a range of Medfly prey densities and illustrate how to use simaR with non-replicated partial data. Applying our method we found a significant effect of temperature on the maximum attack rate of two different guilds of spiders, the orb-weaver $A$. cucurbitina and the ambusher $S$. globosum that was not relevant regarding their attack rate and handling time. Our method compares different predator species and/or experimental conditions in a simple and reproducible procedure through an accurate, easy-to-use, fast and statistically robust analysis, based on simulation and bootstrapping, that can be used to assess the pest suppression potential of predators by simulating their functional responses from low-effort laboratory trials.
\end{abstract}

\section{Introduction}

A classic way of characterizing the predation behavior of a species in terms of prey consumption is through modeling its functional response, i.e. the number of prey consumed or killed by a predator as a function of prey density (Bolker, 2007; Holling, 1959; Solomon, 1949). Predation can be a critical factor affecting prey population dynamics of pest species, thus its accurate description is crucial for practical and applied aspects of biological control (Van Leeuwen et al., 2007).

The attack rate $(a)$ and handling time $\left(\mathrm{T}_{\mathrm{h}}\right)$ are the most common parameters obtained from the functional response models and are widely used to compare the efficiency of a predator species as a natural enemy, or how such an efficiency is affected by differing variables (e.g. Dinis et al., 2016; Gilioli et al., 2005; Pasandideh et al., 2015; Tello Mercado et al., 2017). However, variation within these two parameters can be difficult to interpret in terms of bioecology since they are estimated non-independently of each other. Also, the amount of overlap of their corresponding dispersion measures or interval estimates (e.g. standard deviation and confidence interval) may conceal important ecological patterns only due to low quality datasets (i.e. low replicated and/or incomplete datasets). This fact could lead to misinterpretation of results and affect decision making, for example, selecting a predator as the most efficient against a pest or assessing the effects of a pesticide on the mortality of a selected predator species.

The maximum attack rate $\left(\mathrm{T} / \mathrm{T}_{\mathrm{h}}\right)$, which is the maximum number of prey that can be attacked by a predator or a parasitoid during an interval of time, is a parameter easily calculated using the time interval considered $(\mathrm{T})$ of a functional response experiment and the estimated handling time $\left(\mathrm{T}_{h}\right)$ obtained from modeling the functional response of a predator. This measure also allows evaluating the suppression potential

\footnotetext{
* Corresponding author at: Centro de Investigação de Montanha (CIMO), ESA, Instituto Politécnico de Bragança, Campus de Santa Apolónia, $5300-253$ Bragança, Portugal.

E-mail address: jbenma@hotmail.com (J. Benhadi-Marín).
} 
of a species and it could be used as a stand-alone parameter to make comparisons within a pest control framework since it is directly related to the number of prey killed. However, most published works describe non-replicated experiments and the modeling of a single functional response dataset generates a single point estimator for the maximum attack rate lacking any dispersion measure (e.g. a laboratory experiment conducted during $24 \mathrm{~h}$ and an estimated handling time of $1.5 \mathrm{~h}$, gives a maximum attack rate of $24 / 1.5=16$ prey/day). Accordingly, providing a point estimator without a mean and its dispersion measure reduces its usefulness, especially when comparing experiments with a different $\mathrm{x}$ and $\mathrm{y}$ scales. In fact, in many published works the maximum attack rate is calculated without any dispersion measure or is compared using statistical techniques available from expensive software packages which may limit the number of researchers that could have access to them (e.g. Ahn et al., 2010; Dinis et al., 2016; Mercado et al., 2017).

Simulation based methods have been widely used by ecologists and the number of packages, code and data have been constantly increasing (e.g. Delmas et al., 2017; Réjou-Méchain et al., 2017). Also, within the context of functional response analysis useful tools have been already developed to help estimate the parameters derived from a functional response experiment such as the "frair" package (Pritchard, 2017) for $R$ software (R Core Team, 2016). However, a simulation method to assess and compare directly (e.g. through the maximum attack rate) the potential of different species as natural enemies is still lacking. In addition, the laboratory trials necessary to model a functional response are usually arduous and time consuming because of the difficulty of rearing not only a particular species (e.g. species strongly linked to ecological processes hard to reproduce in laboratory) but also the necessary number of individuals to perform the experiment. This can result in a low number of samples, replicates, or incomplete datasets (e.g. a low number of initial prey densities) that usually causes poor data fitting to the functional response models.

The objectives of this work were (1) to develop a simulation-based method to assess the predatory potential of a species based on the comparison of the maximum attack rate, (2) validate the method, (3) provide an R library to apply the method, and (4) apply the method to two generalist predators fed with a cosmopolitan pest at three temperatures using empirical data as starting point.

Globally, spiders are among the most abundant predators, and their ubiquitous feeding habits upon invertebrate prey qualify them as potential pest control agents in agroecosystems (Benhadi-Marín et al., 2016). The generalist predators selected as model species to apply our method were Araniella cucurbitina (Clerck) (Araneae: Araneidae) and Synema globosum (Fabricius) (Araneae: Thomisidae). The distribution of A. cucurbitina ranges from Europe, Turkey, Central Asia to China and Korea (Nentwig et al., 2018). A cucurbitina is an orb-weaver spider that uses its orbicular web to hunt on trees, bushes and the herbaceous strata (body length male: $3.5-4.5 \mathrm{~mm}$; body length female: $4.5-9.5 \mathrm{~mm}$ ) (Nentwig et al., 2018). S. globosum is a palearctic ambusher spider (body length male: $4 \mathrm{~mm}$; body length female: $6.8-8 \mathrm{~mm}$ ) (Nentwig et al., 2018). Females can be easily observed on flowers, during the day, hunting insect pollinators (Ajuria and Reader, 2014). The selected prey species model was Ceratitis capitata (Wiedemann) (Diptera: Tephritidae). C. capitata, the Mediterranean fruit fly, is a worldwide distributed harmful pest that attacks more than 250 species and affects economically relevant fruit crops such as apple, citrus, figs, peach and pear (Carroll et al., 2002; Weldon et al., 2016).

\section{Material and methods}

\subsection{Origin and rearing of organisms}

Subadult spider females of $S$. globosum were individually hand captured from the flowers of Cistus ladanifer L. located in Cedães $\left(41^{\circ}\right.$ $29^{\prime} 17^{\prime \prime} \mathrm{N} ; 7^{\circ} 07^{\prime} 31^{\prime \prime} \mathrm{W}$ ), northeast of Portugal, in early May 2016. Subadults of $A$. cucurbitina were captured by inspecting low size pine trees around Bragança ( $\left.41^{\circ} 50^{\prime} 19^{\prime \prime} \mathrm{N} ; 6^{\circ} 44^{\prime} 49^{\prime \prime} \mathrm{O}\right)$, northeast of Portugal, during the night in early April 2016.

The spiders were transported into the laboratory in perforated plastic tubes (volume $15 \mathrm{~mL}$ ). Afterwards, they were transferred individually into plastic Petri dishes $(5.2 \mathrm{~cm}$ in diameter and $1.2 \mathrm{~cm}$ height) and maintained in a climate chamber at $21 \pm 1{ }^{\circ} \mathrm{C}, 70 \pm 5 \%$ relative humidity and a photoperiod of 16:8 (L:D) h. Every week, half of a $2 \mathrm{~cm}$ sphere of sodium acrylate hydrogel was placed on the bottom of each Petri dish to provide water. Spiders were fed ad libitum to maturity with adults of $C$. capitata obtained from laboratory cultures maintained at the School of Agriculture of the Polytechnic Institute of Bragança since 2012 (Dinis et al., 2016).

\subsection{Experimental arenas}

Adult spiders were transferred into plastic cages $(7.7 \mathrm{~cm}$ in diameter and $4.3 \mathrm{~cm}$ height) and starved for 7 days. For $A$. cucurbitina no other elements were introduced in the arena since the spiders build their orbweb under the glass Petri dish top. In the case of $S$. globosum a paperboard strip folded in three parts (S-shaped) was placed in the center of each cage to simulate a flower for shelter. The first part $(2 \mathrm{~cm} \times 2 \mathrm{~cm})$ was adhered horizontally to the cage base, the second part $(2 \mathrm{~cm}$ in width and $3 \mathrm{~cm}$ in height) left vertically to the former and acted as stem, and the third one $(2 \mathrm{~cm} \times 2 \mathrm{~cm})$ left horizontally the second one acting as flower. Each cage was covered with a glass Petri dish top ( $9 \mathrm{~cm}$ in diameter) and was used as arena. A hole $(1 \mathrm{~cm}$ in diameter) was opened in the side of each cage and sealed with a cotton ball to facilitate the introduction of prey.

\subsection{Functional response assay}

Four arenas, one spider per arena, and four initial prey densities ( $\mathrm{N}_{0}=3,5,10$ and 40) were used to assess the functional response of $A$. cucurbitina and $S$. globosum on adults of $C$. capitata. Each of the four spiders was used once (i.e. one replicate) per prey density and temperature giving a total of four individuals $\times$ four prey densities $\times$ three temperatures $=48$ individuals per species. Assays were conducted at three different, but constant temperatures $\left(21^{\circ} \mathrm{C}, 24^{\circ} \mathrm{C}\right.$ and $\left.27^{\circ} \mathrm{C}\right)$ at $70 \pm 5 \%$ relative humidity and a photoperiod of $16: 8$ (L:D) h. For the temperatures $24^{\circ} \mathrm{C}$ and $27^{\circ} \mathrm{C}$ the spiders were subjected to an acclimatization period of 7 days, and in all cases, a 7 days period of starvation preceded the functional response experiment. The flies were anesthetized to facilitate manipulation by exposing them to diethyl ether (Panreac, Barcelona, Spain) for $20 \mathrm{~s}$ before being transferred into the arenas (once in the arenas, flies recovered their activity behaving normally after $5 \mathrm{~min}$ in average). After $24 \mathrm{~h}$, the number of flies killed was recorded.

\subsection{Data analysis}

\subsubsection{Functional response analyses}

Statistical analyses were performed using R software (R Core Team, 2016) and were based on the tools available from the "frair" package (Pritchard, 2017). For each dataset (empirical or simulated) we proceed to select the type of functional response in four steps:

Firstly, we fitted the number of prey killed during the time of the experiment to a generic type-I functional response model (a linear increase in attack rate with greater prey density) as:

$\mathrm{N}_{\mathrm{e}} \sim a \times \mathrm{N}_{0} \times \mathrm{T}$

where $\mathrm{N}_{\mathrm{e}}$ represents the number of prey killed, $\mathrm{N}_{0}$ represents the initial prey density, $a$ represents the attack rate (searching efficiency per time), and $\mathrm{T}$ the time of the experiment. For the datasets that did not fit the type-I response we used the frair_test function from "frair" package to determine the final shape of the functional response of the remaining cases. The frair_test function proceeds by fitting two models by logistic 
regression:

Killed/not killed $\sim \alpha+\beta \times$ Density

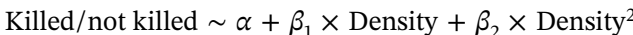

where Density represents the initial prey densities, Killed is the number of prey killed, and not-killed is the difference between them. The function's output provides the sign and $p$-values of the coefficients $\left(\beta_{1}\right.$ and $\beta_{2}$ ) used to select between type-II or type-III response.

A negative linear coefficient $\left(\beta_{1}\right)$ means a better adjustment to typeII functional response (the number of prey killed hyperbolically approaches to an asymptote which represent the maximum attack rate) in which case the most commonly used models are (1) the Holling's type-II predator-prey function (for experiments with prey replacement) (Holling, 1959):

$\mathrm{N}_{\mathrm{e}} \sim\left(a \times \mathrm{N}_{0} \times \mathrm{T}\right) / 1+\left(a \times \mathrm{N}_{0} \times \mathrm{T}_{\mathrm{h}}\right)$

where $\mathrm{N}_{\mathrm{e}}$ represents the number of prey killed, $a$ is the attack rate (searching efficiency per time), $\mathrm{N}_{0}$ is the initial prey density, $\mathrm{T}$ is the time of the experiment and $\mathrm{T}_{\mathrm{h}}$ is the handling time (time to attack, kill and eat each prey), and (2) the Rogers's type-II decreasing prey function (for experiments without prey replacement, i.e. prey depletion) (Rogers, 1972):

$\mathrm{N}_{\mathrm{e}} \sim \mathrm{N}_{0}\left\{1-\exp \left[a\left(\mathrm{~N}_{e} \times \mathrm{T}_{\mathrm{h}}-\mathrm{T}\right)\right]\right\}$

where $\mathrm{N}_{\mathrm{e}}$ represents the number of prey killed, $\mathrm{N}_{0}$ is the initial prey density, $a$ is the attack rate (searching efficiency per time), $T_{h}$ is the handling time and $\mathrm{T}$ the time of the experiment. The fact that $\mathrm{N}_{\mathrm{e}}$ appears in both sides of the equation is due to lacking of prey replacement during the experiment and is solved using the Lambert's transcendental equation (Bolker, 2007).

A positive linear coefficient $\left(\beta_{1}\right)$ and a negative quadratic coefficient $\left(\beta_{2}\right)$ imply that the data fit a type-III functional response (the attack rate (a) is a hyperbolic function of prey density) (see Juliano, 2001) in which case a scaling exponent on the attack rate (a) can be implemented as:

$a \sim b \times \mathrm{N}_{0}^{q}$

where $a$ is the attack rate, $b$ is a search coefficient, $N_{0}$ is the initial prey density, and as $q$ increases ( $q \geq 0$ ), the functional response becomes progressively sigmoid (Vucic-Pestic et al., 2010). This applies for both the Holling's type-II predator-prey function (i.e. assuming prey replacement) and the Rogers's type-II decreasing prey function (not assuming prey depletion).

Secondly, once the type of functional response (type-II or type-III) was selected, we used the frair fit function to fit the data. The frair fit function fits non-linear predator-prey curves to integer data using the 'Nelder-Mead' method for the selected functional response type estimating its parameters (e.g. attack rate $(a)$ and handling time $\left(\mathrm{T}_{\mathrm{h}}\right)$ in the case of a type-II response).

Thirdly, once estimated, the attack rate $(a)$ and handling time $\left(\mathrm{T}_{\mathrm{h}}\right)$ were bootstrapped using the frair_boot function which resamples a previously fitted predator-prey functional response model and provides the $95 \%$ confidence intervals for each parameter. The whole empirical confidence interval for each curve was generated using the drawpoly function that draws a closed polygon delineated by the upper and lower edges given by frair_boot over the plotted curve.

Finally, we calculated the experimental maximum attack rate as $\mathrm{T} /$ $\mathrm{T}_{\mathrm{h}}$ and proceeded to simulate a series of replicates to generate its confidence interval (see Section 2.4.2).

\subsubsection{Simulation for assessing and comparing the prey killing potential of a} predator: The simaR library

An R library consisting of six core functions was developed to run the whole simulation process (Fig. 1). simaR requires a matrix with two columns as input, the first one containing a vector of the initial prey densities and a second one containing a vector of the proportion of prey killed at each initial prey density. The process described in Fig. 1 is performed by simaR once by dataset (in our case study with spiders it is applied six times, one for each of the six species-temperature relationships).

Since each of the prey individual has a certain probability of dying, the pool of discrete data (i.e. the number of prey killed at each initial prey density) is simulated by extracting random values from a binomial distribution with $\mathrm{N}$ equal to the total number of available flies and $p$ equal to the proportion of prey that were killed at each initial prey density. By default, a set of 20 simulated samples and 50 datasets (i.e. 50 simulated replicates) is generated for each study case.

Each set of simulated datasets is then passed to the newTests function to perform and inspect the test of fitting to a type-II or type-III functional response. Then, the user can select between a series of functional response models already implemented in the "frair" package (see below). The handling time $\left(\mathrm{T}_{\mathrm{h}}\right)$ can be approximated by the time of the experiment ( $\mathrm{T}$ ) divided by the number of prey killed as $\mathrm{T} / \mathrm{Ne}_{\max }$, where $\mathrm{Ne}_{\max }$ is the number of prey killed at the highest prey density (Juliano, 2001) and the mean of this value is used by the next function ( getFitData) as starting value for the handling time $\left(\mathrm{T}_{\mathrm{h}}\right)$ to be optimized. By default, the starting value for the attack rate $(a)$ is 0.001 .

According to the results of newTests, the getFitData function allows to select between the following functional response models provided by the "frair" library: (1) Holling's type-II predator-prey function (assuming prey replacement), (2) Rogers's type-II decreasing prey function (not assuming prey replacement), (3) Hassell's original type-III response (assuming prey replacement), (4) Hassell's type-III response (not assuming prey replacement), (5) Scaling exponent response (assuming prey replacement), (6) Scaling exponent response (not assuming prey replacement), and (7) The 'Ecological Models and Data in R' type-II decreasing prey function for more than one predator (assuming prey replacement) (Table S1).

During the former process some outliers could be generated due to the simulation of datasets that poorly fitted the selected functional response model. For example, if the experimental data fit a type-II response and simData generates by chance a simulated dataset that fits better a type-I than a type-II functional response, getFitData will fit the simulated dataset by brute force (since the response type is selected by the user) as a type-II response. Consequently, the handling time $\left(\mathrm{T}_{h}\right)$ for that simulated dataset will be significantly underestimated and accordingly, the value for its estimated maximum attack rate $\left(T / T_{h}\right)$ will be overinflated. The consequence is that the mean of the simulated maximum attack rates may be significantly altered and this bias trespassed to the subsequent bootstrapping process. It is not necessary to inspect the entries in the output of newTests one by one, instead, we suggest to check the presence of outliers within the list of simulated maximum attack rates using the boxplot.stats function and remove them (if any) manually from the getFitData output (that will be passed to Max_attackRates) to ensure accuracy of further calculations.

The simulated curves ( 50 curves by default according to the number of replicates) can be plotted using the plotCurves function to visually inspect the simulation results. Then, the function Max_attackRates calculates the maximum attack rate for each simulated replicate as $\mathrm{T} / \mathrm{T}_{\mathrm{h}}$.

Finally, the mean of the simulated maximum attack rates is bootstrapped using the MARbootstrapping function that calls the boot function from "boot" package running a selected number of bootstrap replicates to generate its $95 \%$ confidence intervals.

\subsection{Validation of simulation method}

The validation of the method was carried according to three objectives: (1) to assess the correspondence between the known (true) maximum attack rate obtained from an artificial dataset and the estimated value provided by simaR, as well as the proportion of cases in which the simulated confidence interval provided by simaR overlapped 


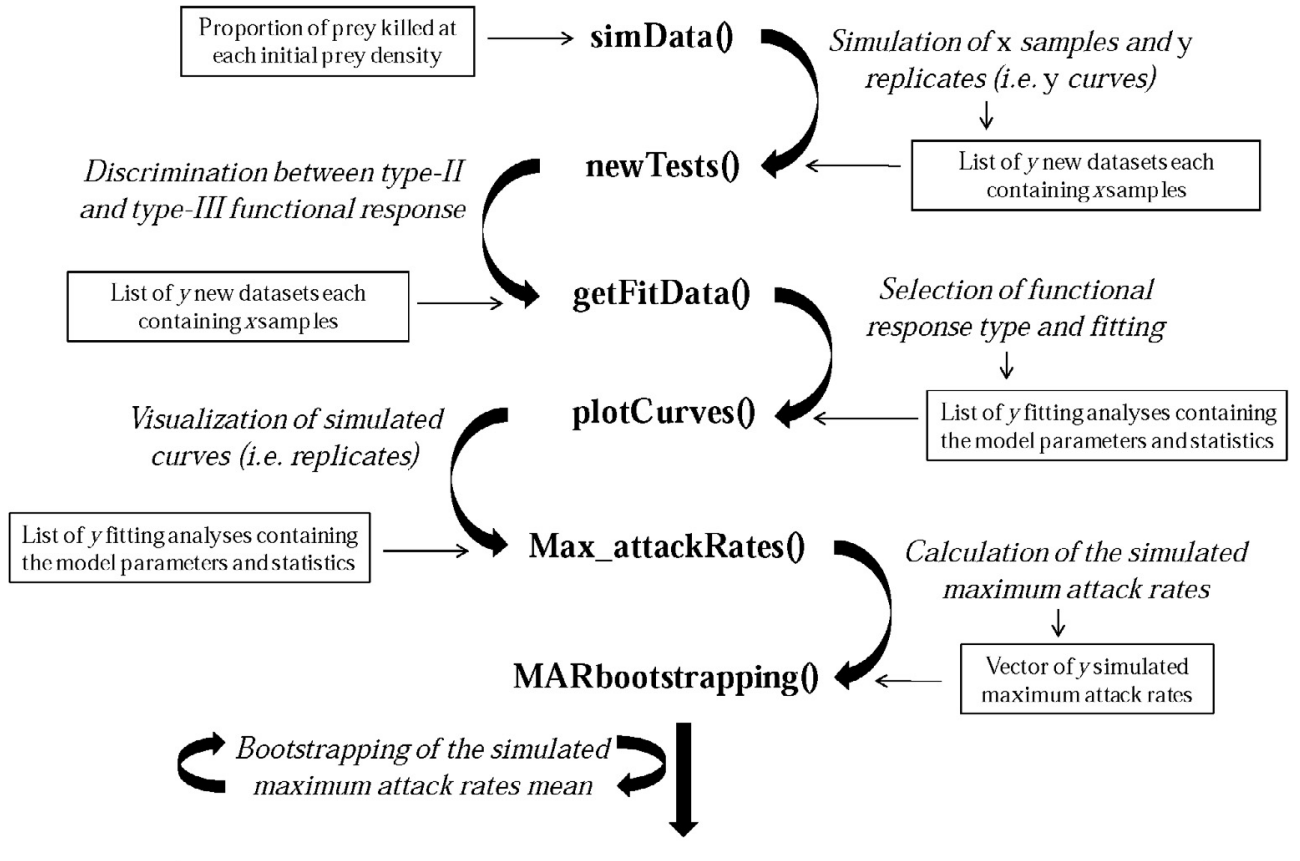

Fig. 1. Workflow with the simaR library. The six core functions are shown in bold. The expected input and the output generated by each function are shown in boxes. The processes carried out by each function are shown in italic. In our case study with spiders the whole process was done six times, one for each of the six species-temperature relationships.

Simulated maximum attack rate mean $\pm 95 \%$ confidence interval

the known (true) value, (2) assess the performance of the method using partial data, and (3) assess the correspondence between the maximum attack rate calculated by simaR and the point estimator for it obtained from literature across different study cases.

\subsubsection{Correspondence between the known and simulated maximum attack rate calculated by simaR}

Since the maximum attack rate is a point estimate calculated from the handling time, we used an artificial dataset generated from a functional response model with known parameters, and then the parameters were estimated back using simaR. For this, we considered 11 initial prey densities $\left(\mathrm{N}_{0}=3,5,10,15,20,25,30,35,40,45\right.$ and 50) assuming prey replacement and their corresponding number of prey killed $\left(\mathrm{N}_{\mathrm{e}}\right)$ were calculated using the Holling's type-II predator-prey function.

We assigned a time of experiment $\mathrm{T}=24 \mathrm{~h}$, an attack rate $a=0.05$, and a handling time $\mathrm{T}_{\mathrm{h}}=1.30$, i.e. a known maximum attack rate $\mathrm{T} / \mathrm{Th}$ of $24 / 1.30=18.46$ prey/day, so that the number of prey killed for each initial prey density was $\mathrm{N}_{\mathrm{e}}=3.00,4.53,7.27,9.11,10.43,11.43$, $12.20,12.82,13.33,13.76$, and 14.12 respectively (Fig. S1A). Then we run 1000 simulations (50 replicates of 20 samples per initial prey density per simulation, i.e. 50.000 simulated datasets) using the simaR library to estimate the maximum attack rate, and the number of times the known maximum attack rate fell within the simulated confidence interval was calculated. Finally, a one sample Student's $t$-test was carried out to check if the real maximum attack rate differed significantly from the simulated ones.

\subsubsection{Performance of simaR on partial data}

We considered 11 initial prey densities $\left(\mathrm{N}_{0}=3,5,10,15,20,25\right.$, $30,35,40,45$ and 50 ) without assuming prey replacement, assigned a proportion of prey killed for each density $\left(\mathrm{p}_{\mathrm{c}}=1,0.9,0.8,0.7,0.6,0.5\right.$, $0.4,0.3,0.3,0.3$ and 0.3 ), and assumed a time of experiment of $\mathrm{T}=24 \mathrm{~h}$. Then, we simulated the number of prey killed for each initial prey density by extracting 10 random values (i.e. 10 samples) from a binomial distribution with $\mathrm{N}=\mathrm{N}_{0}$ and $\mathrm{p}=\mathrm{p}_{\mathrm{c}}$. Then, two series of five and six new datasets respectively were created in two ways: the first series by arbitrary removing a number of initial prey densities $\left(\mathrm{N}_{0}\right)$ from the complete original simulated dataset keeping constant the number of samples (i.e. $\mathrm{n}=10$ ), and the second one by removing the same initial prey densities together with the $50 \%$ of the samples (i.e. $n=5$ ) . We used the frair_test function to assess the type of functional response of the original dataset $\left(\mathrm{N}_{0}=11 ; \mathrm{n}=10\right)$ (Fig. S2A) and its corresponding sample-reduced dataset $\left(\mathrm{N}_{0}=11 ; \mathrm{n}=5\right.$ ) (Fig. S2B). For each of the two datasets, the attack rate $(a)$ and handling time $\left(\mathrm{T}_{\mathrm{h}}\right)$ were estimated using the frair fit function from the "frair" package and the estimated handling time was then used to calculate the empirical maximum attack rates $\left(\mathrm{T} / \mathrm{T}_{\mathrm{h}}\right)$. Finally, the 11 new partial datasets were used together with the original one to apply the simulation method with simaR (Figs. S3 and S4).

Ten simulation runs were carried out for each of the 12 datasets (20 samples and 50 replicates per simulation run) and the effect of the simulation run and number of samples $(n=10$ or $n=5)$ on the simulated maximum attack rate was assessed. We used the Shapiro-Wilk test to check if the simulated data were normally distributed ( $\mathrm{W}=0.853$; $\mathrm{P}<0.001$ ) and then the simulated maximum attack rate was linearly modeled following Zuur et al. (2009) as:

$$
\begin{aligned}
& \varepsilon_{i} \sim \mathrm{N}\left(0, \sigma^{2}\right) \\
& \text { SMAR } \sim \alpha+\beta_{1} \times \text { Run }+\beta_{2} \times \text { Samples }+\beta_{3} \times \text { Run } * \text { Samples }+\varepsilon_{i}
\end{aligned}
$$

were SMAR represents the simulated maximum attack rates, Run represents the number of simulation run, Samples represents the number of samples used at each initial prey density in the original dataset and Run * Samples represents the interaction term between the two independent variables.

\subsubsection{Correspondence between the simaR estimation of the maximum} attack rate and point estimators obtained from literature

We searched for papers focused on the functional response of different natural enemies in different conditions (e.g. response of a natural enemy to different temperatures or response of different natural enemies against the same pest) that provided the mean number of prey attacked at different prey densities. We used the proportion of attacked prey to replicate the analyses conducted in the literature using simaR, and the simulated maximum attack rates $\left(\mathrm{T} / \mathrm{T}_{\mathrm{h}}\right)$ together with their $95 \%$ confidence intervals were generated. Then, in order to check the 
correspondence between the simulated maximum attack rates obtained using simaR and the corresponding ones obtained from literature, the latter were linearly modeled as:

$\varepsilon_{i} \sim \mathrm{N}\left(0, \sigma^{2}\right)$

LiteratureMAR $\sim \alpha+\beta \times \operatorname{simaRMAR}+\varepsilon_{i}$

where MAR represents the maximum attack rates.

\subsection{Application of the simulation method to experimental data with spiders}

We used the "frair" package to select, fit the functional response model, and estimate the corresponding parameters (as described in Section 2.4.1) of each spider-temperature relationship. Then we used the simaR library to simulate and generate the $95 \%$ confidence interval (as described in Section 2.4.2), and compare the maximum attack rate of each spider species between the three selected temperatures. A type-I functional response is supposed to be independent from the handling time, which could be considered unrealistic because the consumption rates cannot continue increasing indefinitely regardless of food density. On the other hand, Batzli et al. (1981) argued that after providing the test organism with the highest food densities found in their natural habitat it would be reasonable to conclude that a type-I response can be exhibited. However, this range of higher prey densities in nature could be unknown for the test organism, which is the case of the two selected spider species selected for this work. Because of this, the type-I responses found along this study were fitted as the increasing part of a Rogers's type-II decreasing prey function (i.e. a type-II response that did not reached the asymptote).

\section{Results}

\subsection{Correspondence between the known and estimated maximum attack} rate calculated by simaR

The known value for the maximum attack rate of the artificial dataset generated to test the correspondence between the known and the simulated parameter was 18.46 prey/day and the maximum attack rate calculated by 1000 simulation runs using simaR was $18.459 \pm 0.003$ (mean $\pm \mathrm{SE}$ ). The lower and upper limit of its simulated 95\% confidence interval were $18.274 \pm 0.003$ (mean \pm SE) and $18.645 \pm 0.003$ (mean \pm SE) respectively. The known maximum attack rate fell 955 times of 1000 simulation runs within the simulated confidence intervals giving a method accuracy of $95.50 \%$ (Table S2) (Fig. S1B) and did not differed significantly from the simulated value $(\mathrm{t}=-0.805, \mathrm{df}=999, \mathrm{P}=0.421)$

\subsection{Performance of simaR on partial data}

The original complete dataset $\left(\mathrm{N}_{0}=11 ; \mathrm{n}=10\right)$ (Fig. S2A) and the corresponding sample-reduced dataset $\left(\mathrm{N}_{0}=11 ; \mathrm{n}=5\right)$ (Fig. S2B) generated to test the method performance on partial data fitted a type-II functional response $\left(\beta_{1}=-0.0515 ; Z=15.473 ; P<0.001\right.$, and $\beta_{1}=-0.052 ; Z=-10.982 ; P<0.001$ respectively). Accordingly, the Rogers's type-II decreasing prey function was fitted for each dataset giving a coefficient of attack rate of $a=0.148 \pm 0.020$ (estimate \pm SE) $(\mathrm{Z}=7.552 ; \quad \mathrm{P}<0.001)$, an estimated handling time of $\mathrm{T}_{\mathrm{h}}=1.68 \pm 0.071$ (estimate $\left.\pm \mathrm{SE}\right)(\mathrm{Z}=23.719 ; \mathrm{P}<0.001)$, and an empirical maximum attack rate of $\left(\mathrm{T} / \mathrm{T}_{\mathrm{h}}\right)$ of 14.29 prey/day for the original complete dataset. The sample-reduced dataset $\left(\mathrm{N}_{0}=11\right.$; $\mathrm{n}=5$ ) generated a coefficient of attack rate $(a)$ of $0.149 \pm 0.030$ (estimate $\pm \mathrm{SE})(\mathrm{Z}=5.130 ; \mathrm{P}<0.001)$, an estimated handling time $\left(\mathrm{T}_{\mathrm{h}}\right)$ of $1.742 \pm 0.105$ (estimate $\left.\pm \mathrm{SE}\right)(\mathrm{Z}=16.553 ; \mathrm{P}<0.001)$, and an empirical maximum attack rate $\left(\mathrm{T} / \mathrm{T}_{\mathrm{h}}\right)$ of 13.777 prey/day.

The simulated maximum attack rates were $14.23 \pm 0.01$ (mean \pm SE) and $14.11 \pm 0.08$ (mean \pm SE) for the pool of datasets with 10 samples and 5 samples respectively (Table S3). The simulation run number had not a significant effect on the simulated maximum attack rate estimation ( $\mathrm{F}=0.779 ; \mathrm{df}=1 ; \mathrm{P}=0.379$ ) (Fig. S5A). The number of samples (n) of each dataset did not affected significantly the estimation of the parameter $(\mathrm{F}=1.535 ; \mathrm{df}=1 ; \mathrm{P}=0.218$ ) (Fig. S5B), and the interaction between the two variables was not significantly as well $(\mathrm{F}=0.494 ; \mathrm{df}=1 ; \mathrm{P}=0.484)$.

\subsection{Correspondence between the simaR estimation of the maximum attack} rate and point estimators obtained from literature

Regarding the values for the maximum attack rate extracted from literature, we found six papers focused on the functional response of different groups of natural enemies (seven species of predators and one parasitoid) in different conditions that used three types of functional response to fit the data and that provided the mean of the number of attacked prey at each initial prey density (Table S4). The results reported in these papers were used together with the re-analysis of the functional response data of our previous paper on the pest suppression potential of two species of carabids (Dinis et al., 2016; Table S4). The linear regression carried out between the simulated maximum attack rates obtained using the simaR library on their corresponding bibliographic maximum attack rates gave a coefficient of determination $\left(\mathrm{R}^{2}\right)$ of 0.932 (Fig. S6).

\subsection{Application of the simulation method to experimental data with spiders}

The estimated parameters from the logistic regression analysis of the empirical proportion of $C$. capitata adults killed by adult females of A. cucurbitina and $S$. globosum indicated a type-II functional response at each tested temperature except for the former species at $21^{\circ} \mathrm{C}$ which showed a type-I functional response (Table 1 ). The highest number of killed preys was obtained at $21^{\circ} \mathrm{C}$ with A. cucurbitina (Fig. 2A) whereas the lowest one was observed in S. globosum at $21^{\circ} \mathrm{C}$ (Fig. 2B). Almost the total of the simulated curves ranged within the empirical confidence intervals of the empirical curves for both A. cucurbitina and S. globosum (Fig. 3) although the simulated range of curves differed slightly from the empirical one in the case of $A$. cucurbitina at $21^{\circ} \mathrm{C}$ (Fig. 3A).

The coefficient of attack rate $(a)$ corresponding to the type-I response of $A$. cucurbitina at $21^{\circ} \mathrm{C}$ was the lowest one across the six spidertemperature relationships (Table 1), however it was not significantly different along the gradient of temperature for this species (Fig. 4A). The estimated handling time $\left(\mathrm{T}_{\mathrm{h}}\right)$ of $A$. cucurbitina was not significantly different between $24^{\circ} \mathrm{C}$ and $27^{\circ} \mathrm{C}$ (Table 1) (Fig. 4B). The simulated maximum attack rate of $A$. cucurbitina was significantly higher at $21^{\circ} \mathrm{C}$ when compared to $24^{\circ} \mathrm{C}$ and $27^{\circ} \mathrm{C}$, however, it was not significantly different between the two latter temperatures (Fig. 4C).

In the case of $S$. globosum both the attack rate and handling time decreased across the increasing gradient of temperatures (Table 1). However, based on the overlapping of the $95 \%$ confidence intervals, no significant differences in attack rate or handling time could be observed (Fig. 4D and E), except for the handling time at $21^{\circ} \mathrm{C}$ and $27^{\circ} \mathrm{C}$ where the former was significantly higher than the latter (Fig. 4E). Finally, significant differences between the simulated maximum attack rates among the three temperatures were found for $S$. globosum increasing from $21^{\circ} \mathrm{C}$ to $27^{\circ} \mathrm{C}$ (Table 1) (Fig. 4F).

\section{Discussion}

\subsection{Method validation and performance}

We developed a method to assess the prey killing capacity of a predator which uses the maximum attack rate $\left(\mathrm{T} / \mathrm{T}_{\mathrm{h}}\right)$, a parameter derived from the functional response of a species under selected experimental conditions, to evaluate the capacity of a predator or a parasitoid to attack a number of prey individuals during a given time. 
Table 1

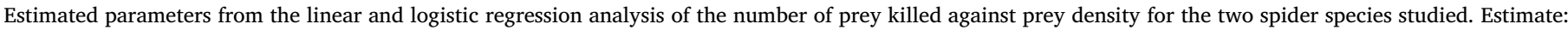

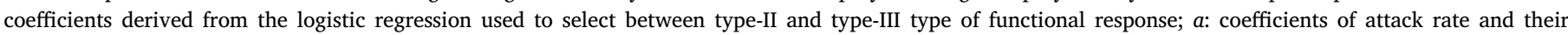

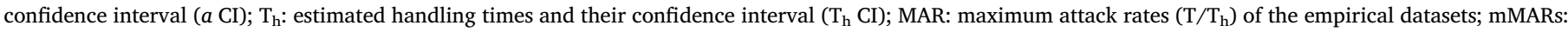

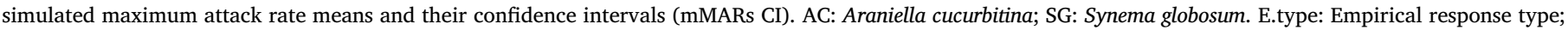

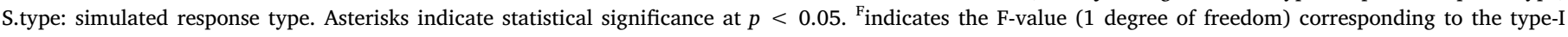
functional response fitting.

\begin{tabular}{|c|c|c|c|c|c|c|c|c|c|c|c|c|c|c|}
\hline Predator & Temperature & Estimate & Std. Error & Z-value & $\mathrm{P}$ & $a$ & $a \mathrm{CI}$ & $\mathrm{T}_{\mathrm{h}}$ & $\mathrm{T}_{\mathrm{h}} \mathrm{CI}$ & MAR & mMARs & mMARs CI & E.type & S.type \\
\hline \multirow[t]{3}{*}{ AC } & $21^{\circ} \mathrm{C}$ & 0.5031 & 0.0267 & $354.36^{\mathrm{F}}$ & $<0.001^{*}$ & 0.0230 & $\begin{array}{l}0.0210 \\
0.0250\end{array}$ & - & - & - & 86.7388 & $\begin{array}{l}78.5528 \\
95.0345\end{array}$ & I & II \\
\hline & $24^{\circ} \mathrm{C}$ & -0.0439 & 0.0093 & -4.7303 & $<0.001^{*}$ & 0.0620 & $\begin{array}{l}0.0370 \\
0.0910\end{array}$ & 1.2820 & $\begin{array}{l}0.8800 \\
1.6250\end{array}$ & 18.7207 & 18.9839 & $\begin{array}{l}18.4930 \\
19.4728\end{array}$ & II & II \\
\hline & $27^{\circ} \mathrm{C}$ & -0.0333 & 0.0090 & -3.7097 & $<0.001^{*}$ & 0.0470 & $\begin{array}{l}0.0280 \\
0.0820\end{array}$ & 1.2820 & $\begin{array}{l}0.7200 \\
2.0500\end{array}$ & 18.7207 & 19.1139 & $\begin{array}{l}18.4856 \\
19.7602\end{array}$ & II & II \\
\hline \multirow[t]{3}{*}{ SG } & $21{ }^{\circ} \mathrm{C}$ & -0.0507 & 0.0095 & -5.3174 & $<0.001^{*}$ & 0.0570 & $\begin{array}{l}0.0440 \\
0.1000\end{array}$ & 2.7010 & $\begin{array}{l}2.1860 \\
4.1220\end{array}$ & 8.8856 & 8.9710 & $8.6191,9.3314$ & II & II \\
\hline & $24^{\circ} \mathrm{C}$ & -0.0286 & 0.0091 & -3.1590 & $0.0016^{*}$ & 0.0370 & $\begin{array}{l}0.0180 \\
0.1230\end{array}$ & 1.5820 & $\begin{array}{l}0.5760 \\
6.8580\end{array}$ & 15.1707 & 15.7094 & $\begin{array}{l}15.0262 \\
16.3917\end{array}$ & II & II \\
\hline & $27^{\circ} \mathrm{C}$ & -0.0188 & 0.0088 & -2.1363 & $0.0327^{*}$ & 0.0320 & $\begin{array}{l}0.0230 \\
0.0480\end{array}$ & 0.8040 & $\begin{array}{l}0.1110 \\
1.6320\end{array}$ & 29.8507 & 31.8333 & $\begin{array}{l}30.0105 \\
33.6730\end{array}$ & II & II \\
\hline
\end{tabular}

The development of this method was born from the need to make statistical hypothesis testing using experimental data with a low number of samples, low replicated assays, or even partial data in the context of predator functional response research. We selected the confidence interval method to test hypotheses because of its ability to help quantify the magnitude of an effect in units of scientific interest (Jiroutek et al., 2003).

The way to generate the confidence intervals was through simulation, a method that allows to recreate a selected number of both samples and replicates, followed by bootstrapping that allows to resample data matrices and generate dispersal measures around an estimate (e.g. the mean) at a desired level of confidence (usually 95\%). We provided the simaR library that run the whole process using an experimental approximation of the handling time $\left(\mathrm{T} / \mathrm{Ne}_{\max }\right)$ as starting value to parameterize the simulated handling time, which in turn is used to calculate the simulated maximum attack rate and its $95 \%$ confidence interval.

It is important to say that the resulting intervals should be proper confidence intervals or at least good approximations (i.e. a $95 \%$ confidence interval should overlap the known value with a probability of 95\%). Commonly, the true values are not known since the parameter to be simulated and for which we want to provide confidence intervals is an estimate itself (e.g. the handling time). Accordingly, we validated the method by fabricating an artificial dataset with known parameters

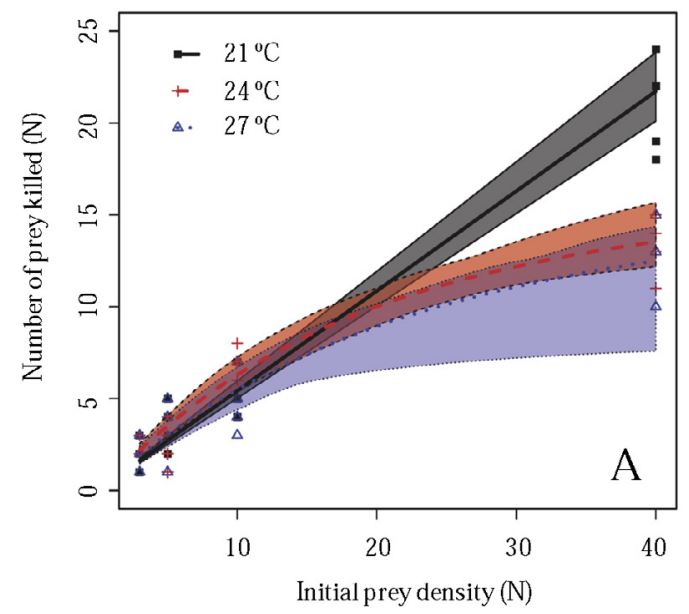

and estimated the parameters back reaching an accuracy of $95.50 \%$. Moreover, when testing the performance of the method using partial data, we found consistency on the parameters estimation by simulation, i.e. the maximum attack rate and the lower and upper bound of its confidence interval. This suggest that the effect of gaps in the data can be solved by using a selected number of simulated samples and replicates (in our case 20 and 50 respectively). Also, when only the means of the number of prey killed were available (i.e. bibliographical sources) our method loosed only a $6.80 \%$ of information.

When comparing our experimental and simulated data for spiders we also found a good overlap between the simulated range of curves (i.e. replicates) and the experimental data despite a slight difference in the case of $A$. cucurbitina at $21{ }^{\circ} \mathrm{C}$ because the fitted models were different, i.e. type-I (empirical) and type-II (simulated).

\subsection{Method limitations}

In general, our method allows a fast and accurate comparison of the maximum attack rates of different study cases; however, some points have to be stressed. We used the known value of the simulated parameter to validate the method and an ad-hoc sample size and number of replicates for simulation (20 and 50 respectively), since a confidence interval that includes the true parameter value may slightly differ from a confidence interval that does not include it (Beal, 1989), further

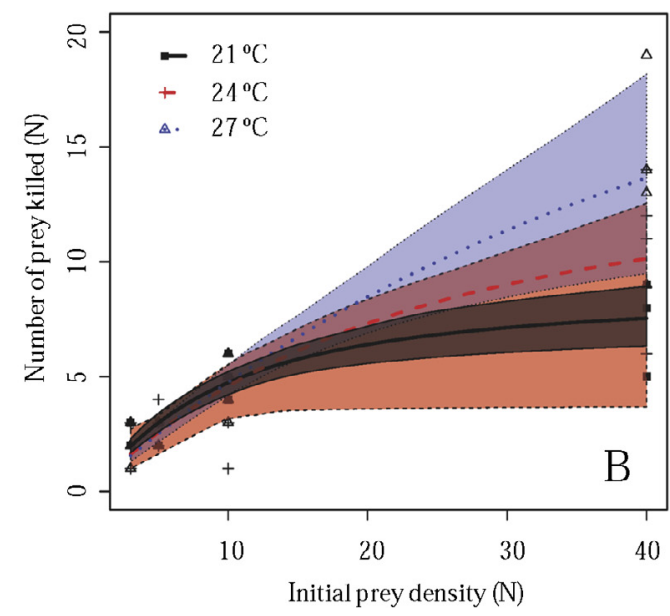

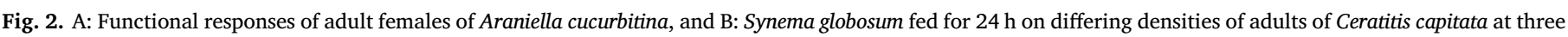

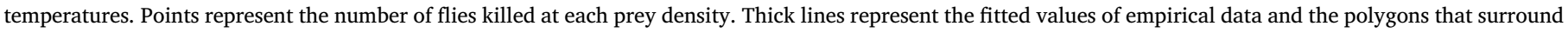
them represent the limits of the confidence interval of the empirical curves for each temperature. 

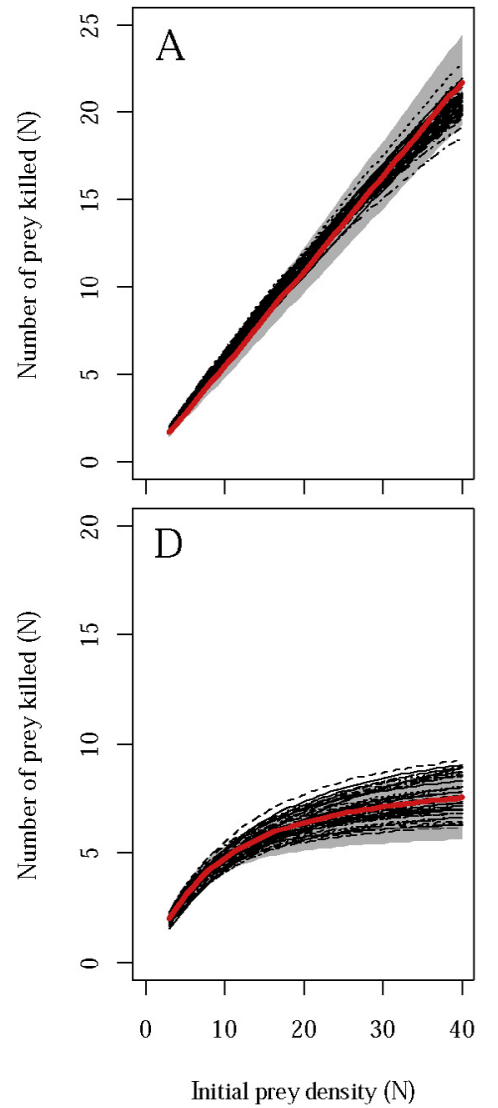
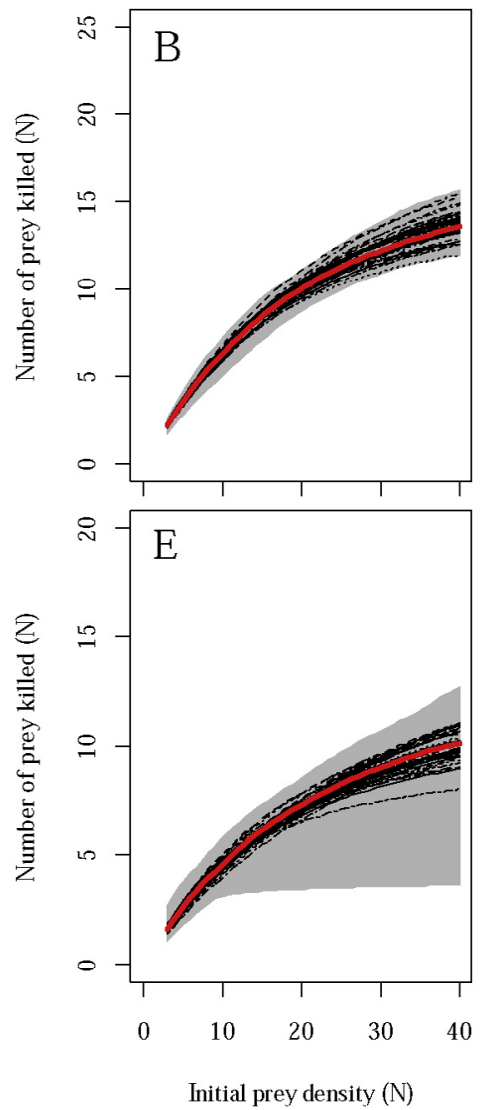
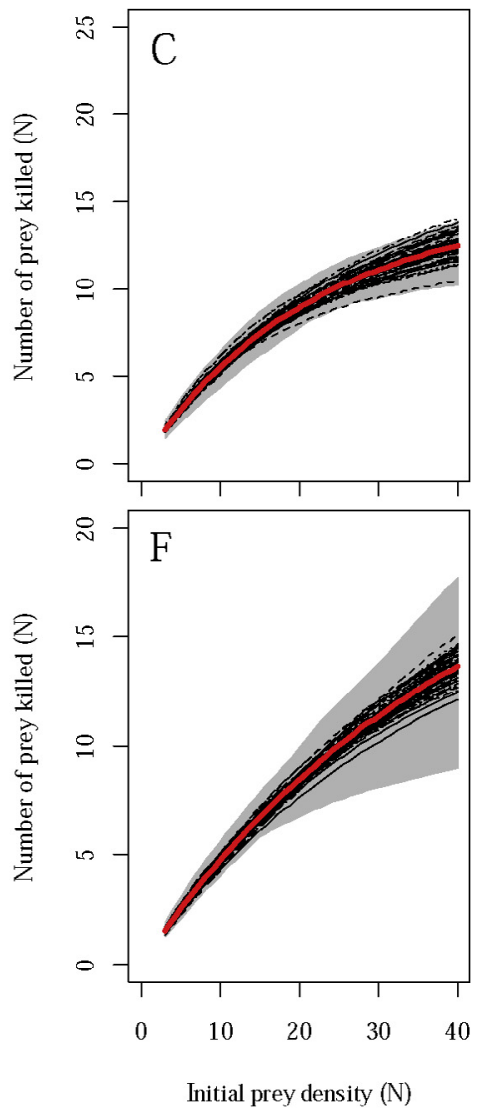

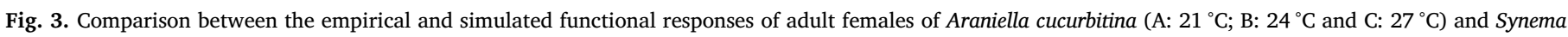

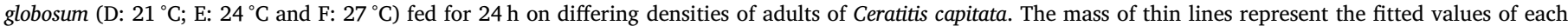

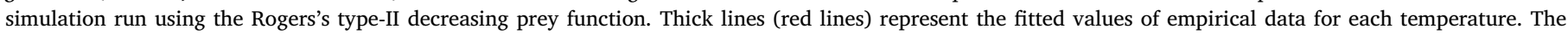

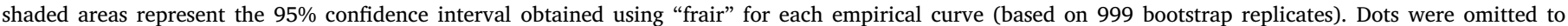
facilitate visualization. (For interpretation of the references to colour in this figure legend, the reader is referred to the web version of this article.)

combination of simulation runs should be carried out to test in which extent the number of simulated samples and simulated replicates may affect the size of the confidence interval, for example, is a simulation of 20 samples and 50 replicates significantly different from another one of 10 samples and 100 simulations? In which cases such a combination is more accurate and/or appropriate? In addition, extracting random values from the binomial distribution is an approximation and the assumption of independence between the fates of individual prey should be investigated in the future.

We used simulated data to validate the method toward the estimation of a biological parameter such as the maximum attack rate using empirical data. Since no ecological information is represented by the initial artificial dataset beyond the fit to a selected model, it could be argued that the method can be applied to any species under any laboratory conditions that the code allows to select (i.e. time of the experiment, number of predators, prey replacement, and type of functional response). However, conclusions derived from different functional response analyses must be carefully drawn since variation in physical and biological conditions of the studied system such as starvation before the experiment, arena size, and acclimatization period are not taken into account by the model equations and may lead to ecological misinterpretations. For instance, in which extent the conclusions of a laboratorial experiment on functional response can be extrapolated to the field?

Since natural assemblages have multiple prey species that are subjected to seasonal processes, key community-related concepts such as food preference and prey preference (Wise et al., 2006), behavioral differences among conspecifics (Toscano and Griffen, 2014), successional processes (Settle et al., 1996), intraguild competition and prey availability (Perkins et al., 2018) and predator-prey body size proportion (Shimazaki and Miyashita, 2005) can have implications for ecosystem functioning and stability and should also be considered within the context of functional response modeling.

Finally, the simaR library contemplates a type-II decreasing prey function for multiple predators, but multispecies functional response models are not currently included. Nevertheless, development of methods accounting for multiple prey functional responses and predator and prey behavior are of growing interest (e.g. Scharf et al., 2008; Smout et al., 2010). Accordingly, within the context of biological control, further research is needed to test under which situations the parameters of the functional response models and their derivates such as the maximum attack rate could be suitable stand-alone surrogates of the suppression potential of a biological control agent.

\subsection{Bioecological interpretation of the effect of temperature on the spiders functional response}

Since temperature is a key driver in pest control, e.g. high temperature usually hinders the natural enemies action in greenhouses (Gilioli et al., 2005; Vacante, 2000), we applied our method to experimental data obtained in the laboratory at different temperatures $\left(21,24\right.$ and $27^{\circ} \mathrm{C}$ ) on two widespread species of generalist predators, the orb-weaver spider A. cucurbitina and the ambusher spider $S$. globosum against the pest $C$. capitata.

The maximum attack rate of $A$. cucurbitina decreased dramatically from $21^{\circ} \mathrm{C}$ to $24^{\circ} \mathrm{C}$ and was not significantly different from the latter temperature to $27^{\circ} \mathrm{C}$. This reduction in the efficiency of capturing prey according to the temperature by orb-weavers have been well 

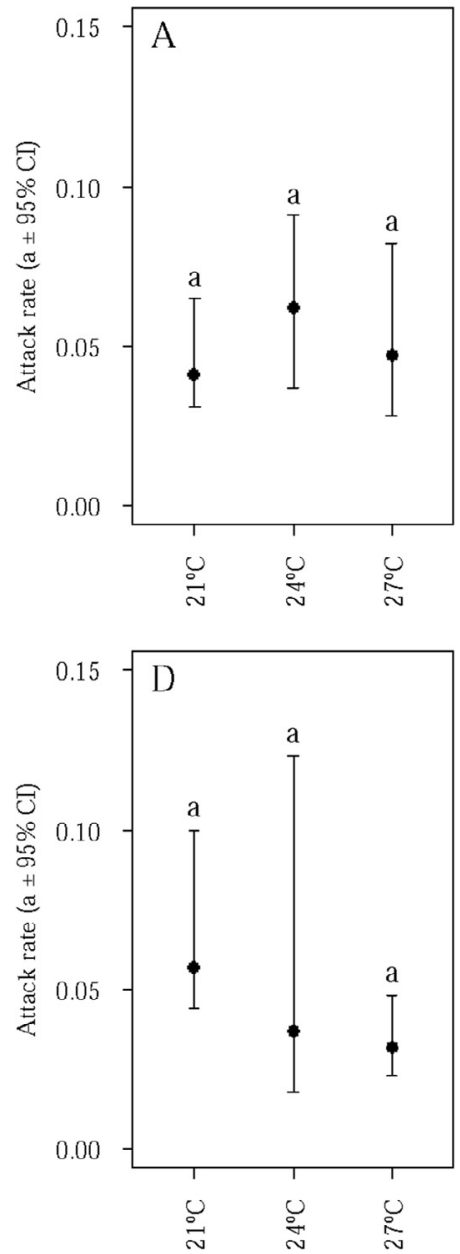
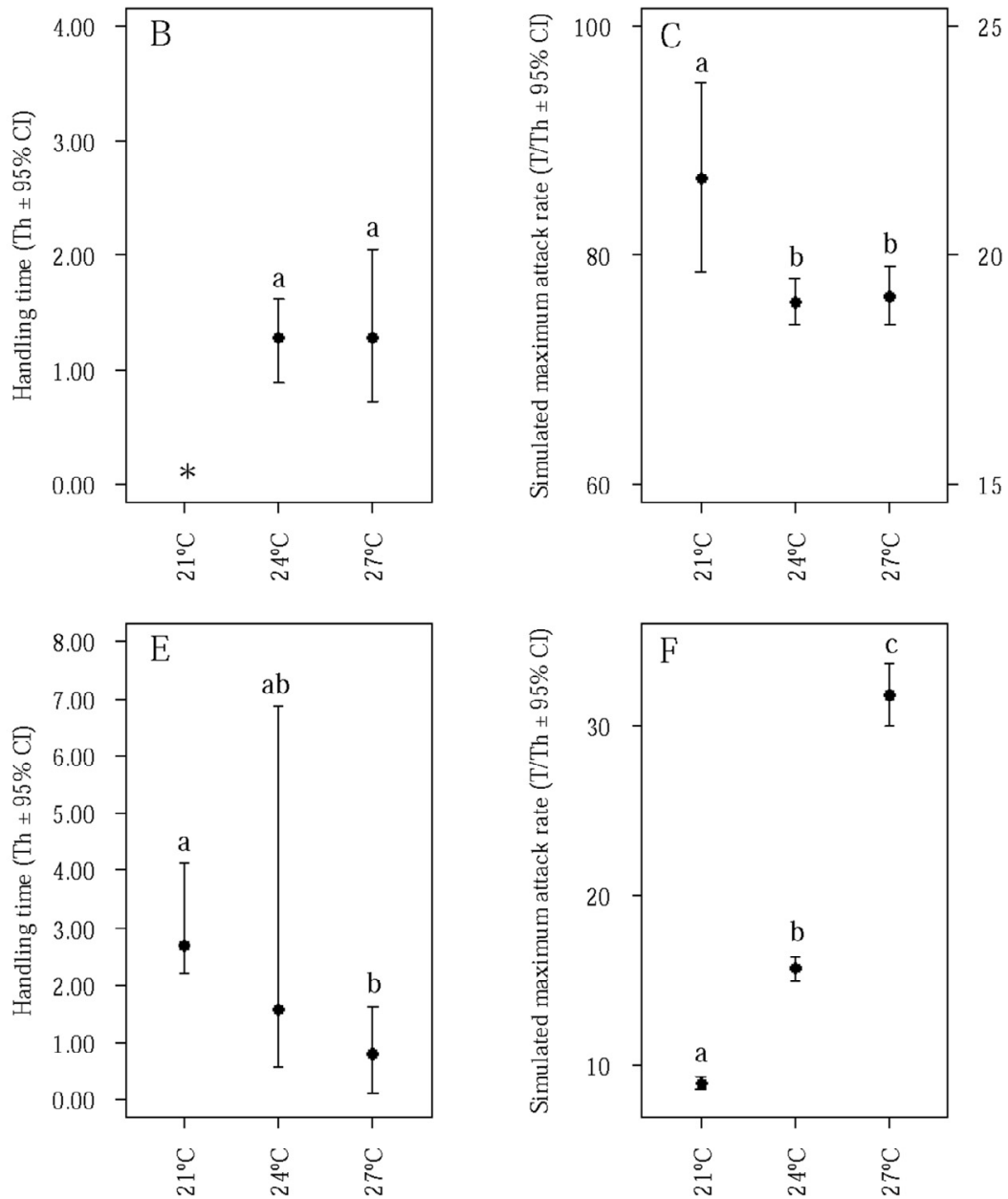

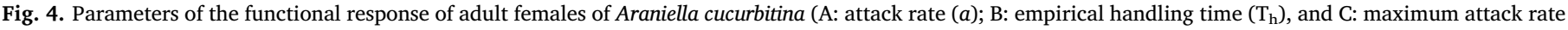

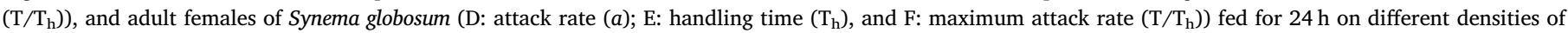

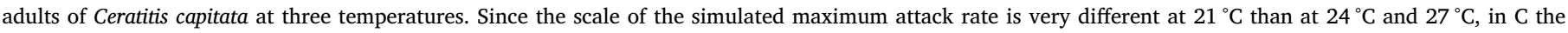

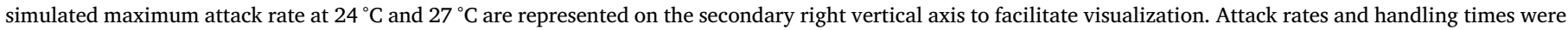

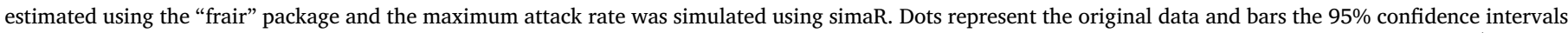

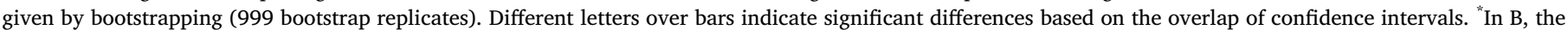
handling time at $21^{\circ} \mathrm{C}$ is empty because the fitted model was of type-I.

documented from different points of view. Hesselberg and Vollrath (2006) performed an experiment with Araneus diadematus Clerck (Araneae: Araneiade) against Drosophila melanogaster Meigen (Diptera: Drosophilidae) and hypothesized that flying insects had a higher body temperature because of the flight whereas the spiders had a lower body temperature waiting in the centre on their web. In our experiment, this difference in body temperature could make the escape time of $C$. capitata significantly faster at 24 and $27^{\circ} \mathrm{C}$. In addition, the web building architecture of $A$. diadematus was also found to be significantly different at lower temperatures by Vollrath et al., (1997) and suggested that the increase in spiral spacing could be an adaptation to larger sized prey supposedly able to fly at lower temperatures.

Hunting success of orb-weavers relies on their web efficiency. The capture threads of this web are coated with glues droplets composed by an adhesive viscoelastic glycoprotein covered by an aqueous solution. This aqueous glue, plasticizes the silk and provides elasticity from the surface tension of the liquid (Vollrath and Edmonds, 1989). However, environmental changes in temperature have the potential to alter thread and web function, and Stellwagen et al. (2014) found that an increase in temperature decreased the glycoprotein viscosity of the thread build by Argiope aurantia Lucas (Araneae: Araneidae). This effect may also alter the mechanical properties of the webs of A. cucurbitina significantly decreasing the efficiency in capturing prey at high temperatures.

Moreover, biomechanical properties of silks and structural diversity of spider webs are highly variable and also depends on rate of spinning, $\mathrm{pH}$ levels in the silk glands, humidity and temperature (Harmer et al., 2011). In fact, the dependency of spider webs on environmental and physiological conditions is not exclusive of orb-weavers. Barghusen et al. (1997) suggested that Achaearanea tepidariorum C.L. Koch (Araneae: Theridiidae), an aerial space web builder (Uetz et al., 1999) optimizes web construction by temperature selection and found an optimal experimental temperature at $20^{\circ} \mathrm{C}$ at which the spiders produced the heaviest webs and prey capture should be maximized.

In our experiment, $S$. globsoum, a sit-and-wait active hunter (i.e. ambusher without web device) showed a clear significant increasing pattern of the maximum attack rate from the lowest to the highest temperature tested. This gradient in hunting success could be explained in terms of the effect of temperature in both the predator and the prey. As for orb-weavers, the fact that an ambusher spider waits for its prey can result in a difference between the body temperature of the predator and the prey thus being advantageous for the flying insect. Booster et al. (2015) hypothesized that at lower temperatures, the movement of the spider leg joints could be less coupled because of increased hemolymph viscosity thus slowing the flow of hemolymph, and demonstrated that at high temperature the spiders ran the fastest with the highest stride 
frequencies using Aphonopelma hentzi (Jean-Étienne Girard) (Araneae: Theraphosidae) as model species.

The hunting behavior of a crab spider such as $S$. globosum consists of standing still with the first and second pair of legs (raptorial forelimbs) extended while waiting for a prey. When a prey approximates enough, the spider rapidly grabs it and brings it close to the mouthparts to be bitten. The effect of temperature on the hemolymph viscosity may improve the ability of $S$ globosum to catch a fly by increasing the attack movement velocity at higher temperatures. However, Schmalhofer and Casey (1999) found that temperature did not affect the hunting performance of the crab spiders Misumenops asperatus (Hentz) (Araneae: Thomisidae) and Misumenoides formosipes (Walckenaer) (Araneae: Thomisidae) on Musca domestica (L.) (Diptera: Muscidae). On the contrary, they reported a slight effect of temperature on the amount of time spent moving by the flies. Also, the prey were exposed to predators at set densities and within confined arenas, so that effect of encounter rate was irrelevant. As explained by Kruse et al. (2008), predator hunting success depends on the encounter rate with prey, prey escape ability, and predator agility; they also found that the predation rate of Pardosa prativaga (L. Koch) (Araneae: Lycosidae) and Clubiona phragmitis (L. Koch) (Araneae: Clubionidae) increased with temperature, their prey $D$. melanogaster being more active at the highest temperatures. This positive relationship between predation rate and prey activity on an increasing gradient of temperature can also explain our results for the significant increase of the maximum attack rate of $S$. globosum on $C$. capitata from $21^{\circ} \mathrm{C}$ to $27^{\circ} \mathrm{C}$.

The two spider species we used to study the effect of temperature on the functional response use a sit-and-wait strategy to hunt. Overall, their attack rate and handling time were not significantly different across the studied temperatures. However, the handling time of $S$. globosum was significantly reduced from $21^{\circ} \mathrm{C}$ to $27^{\circ} \mathrm{C}$ suggesting a pattern that was then clearly uncovered by our method when we focused on the maximum attack rates. This highlights the relevance of the former parameter on studies related to biological pest control. Hence, differences in the functional response of these species resulted in an opposite pattern in the efficiency as predators against $C$. capitata along a gradient of temperature. Moreover, populations and food-web dynamics may depend on slight differences in functional response parameters (Vucic-Pestic et al., 2010) which may have important implications, for instance, in a climate change scenario.

\section{Conclusions}

In this work we showed how to obtain reliable and accurate simulated data and draw conclusions through simulation starting from loweffort laboratory trials (in our case only four samples and one replicate per spider species) within the context of functional response analysis. This enables a fast and direct comparison between the efficiency of different species of natural enemies in terms of the maximum attack rate under different conditions. Accordingly, research on functional responses under different environmental conditions and for different species of predators, parasitoids and their prey is crucial to increase the efficiency of biological pest control programs. In the case of spiders, known variables affecting pest suppression, such as mechanical silk properties, web architecture, humidity, body and environmental temperature, encounter rate, and prey behavior, need to be better investigated to determine their effects upon capture rate. We provided the simaR library in the highly extensible and Open Source R language that automates each step of a simulated functional response experiment based on real data. Using a bootstrapping process, the pest suppression potential of predators can be easily compared between potential natural enemies starting from low effort laboratory trials. This method could represent a powerful tool for using in the sustainable farming system context. However, it is not limited to pest control studies. In fact, it can be used to develop basic research on the biology of species and apply it to study the effects of climatic change on population dynamics and also to provide valuable data for powerful individual based models (IMBs) that are of increasing interest nowadays such as ALMASS (Topping et al., 2003) and (Bilbao-Castro et al., 2015).

\section{Authors' contributions}

J.B.M., S.A.P.S. and J.A.P. conceived and designed the functional response experiments, J.B.M. developed the R functions, D.B. collected the spiders in the field and provided assistance during the laboratory experiments, J.P.S. reviewed and tested the code and all the authors contributed to writing the paper.

\section{Data accessibility}

The empirical functional response datasets used to test the code (Synema_dataset.txt and Araniella_dataset.txt), the simaR library (simaR_v05.R) and an example R file for type-II and type-III functional responses (Example_simaR.R) are available from https://github.com/ jbenma/simaR/tree/Simulation-functions.

\section{Acknowledgments}

The authors are grateful to the Portuguese Foundation for Science and Technology for financial support through the project EXCL/AGR$\mathrm{PRO} / 0591 / 2012$ "Olive crop protection in sustainable production under global climatic changes: linking ecological infrastructures to ecosystem functions". Jacinto Benhadi-Marín thanks FCT for the Ph.D. grant SFRH/BD/97248/2013. This manuscript is part of Jacinto Benhadi-Marín's Ph.D. thesis. The authors would like to thank the editor and reviewers for their valuable comments and have no conflicts of interest to declare.

\section{Appendix A. Supplementary data}

Supplementary data associated with this article can be found, in the online version, at http://dx.doi.org/10.1016/j.biocontrol.2018.05.007.

\section{References}

Ahn, J.J., Kim, K.W., Lee, J.-H., 2010. Functional response of Neoseiulus californicus (Acari: Phytoseiidae) to Tetranychus urticae (Acari: Tetranychidae) on strawberry leaves. J. Appl. Entomol. 134, 98-104.

Ajuria, H., Reader, T., 2014. Female-limited colour polymorphism in the crab spider Synema globosum (Araneae: Thomisidae). Biol. J. Linn. Soc. 113 (2), 368-383.

Barghusen, L.E., Claussen, D.L., Anderson, M.S., Bailer, A.J., 1997. The effects of temperature on the web-building behaviour of the common house spider, Achaearanea tepidariorum. Funct. Ecol. 11, 4-10.

Batzli, G.O., Jung, H.-J.G., Guntenspergen, G., 1981. Nutritional ecology of microtine rodents: linear foraging-rate curves for brown lemmings. Oikos 37, 112-116.

Beal, S.L., 1989. Sample size determination for confidence intervals on the population mean and on the difference between two population means. Biometrics 45, 969-977.

Benhadi-Marín, J., Pereira, J.A., Bento, A., Sousa, J.P., Santos, S.A.P., 2016. Biodiversity of spiders in agroecosystems: community structure, conservation and roles as biological control agents. 43-110 In: Santos, S.A.P. (Ed.), Natural Enemies: Identification, Protection Strategies and Ecological Impacts. Nova Science Publishers, pp. 153.

Bilbao-Castro, J.R., Barrionuevo, G., Ruiz-Lupión, D., Casado, L.G., Moya-Laraño, J., 2015. Weaver, A Multiagent, Spatial-Explicit and High-Performance Framework to Study Complex Ecological Networks. In: International Conference on Practical Applications of Agents and Multi-Agent Systems. PAAMS 2015, Highlights of Practical Applications of Agents, Multi-Agent Systems, and Sustainability - The PAAMS Collection. pp. 139-150.

Bolker, B., 2007. Ecological Models and Data in R. Princeton. Princeton University Press, New Jersey.

Booster, N.A., Su, F.Y., Adolph, S.C., Ahn, A.N., 2015. Effect of temperature on leg kinematics in sprinting tarantulas (Aphonopelma hentzi): high speed may limit hydraulic joint actuation. J. Exp. Biol. 218, 977-982.

Carroll, L.E., White, I.M., Freidberg, A., Norrbom, A.L., Dallwitz, M.J., Thompson, F.C., 2002. Pest fruit flies of the world. Version: 8th December 2006. Available at: http:// delta-intkey.com (accessed 15.09.2017).

Delmas, E., Brose, U., Gravel, D., Stouffer, D.B., Poisot, T., 2017. Simulations of biomass dynamics in community food Webs. Methods Ecol. Evol. 8, 881-886.

Dinis, A.M., Pereira, J.A., Benhadi-Marín, J., Santos, S.A.P., 2016. Feeding preferences and functional responses of Calathus granatensis and Pterostichus globosus (Coleoptera: Carabidae) on pupae of Bactrocera oleae (Diptera: Tephritidae). Bull. Entomol. Res. 
106 (6), 701-709

Fathipour, Y., Karimi, M., Farazmand, A., Talebi, A.A., 2017a. Age-specific functional response and predation rate of Amblyseius swirskii (Phytoseiidae) on two-spotted spider mite. Syst. Appl. Acarol. 22 (2), 159-169.

Fathipour, Y., Karimi, M., Farazmand, A., Talebi, A.A., 2017b. Age-specific functional response and predation capacity of Phytoseiulus persimilis (Phytoseiidae) on the twospotted spider mite. Acarologia 58 (1), 31-40.

Gilioli, G., Baumgärtner, J., Vacante, V., 2005. Temperature influences on functional response of Coenosia attenuata (Diptera: Muscidae) individuals. J. Econ. Entomol. 98 (5), 1524-1530.

Harmer, A.M.T., Blackledge, T.A., Madin, J.S., Herberstein, M.E., 2011. High-performance spider webs: integrating biomechanics, ecology and behavior. J. R. Soc Interface 8, 457-471.

Hassell, M., Lawton, J., Beddington, J., 1977. Sigmoid functional responses by invertebrate predators and parasitoids. J. Anim. Ecol. 46, 249-262.

Hesselberg, T., Vollrath, F., 2006. Temperature affects both web spider response time and prey escape speed. Bull. Br. Arachnol. Soc. 13 (7), 275-280.

Holling, C.S., 1959. Some characteristics of simple types of predation and parasitism“. Can. Entomol. 91 (7), 385-398.

Jiroutek, M.R., Muller, K.E., Kupper, L.L., Stewart, P.W., 2003. A new method for choosing sample size for confidence interval-based inferences. Biometrics 59, 580-590.

Juliano, S.A., 2001. Nonlinear curve fitting: predation and functional response curve. pp. 178-196. In: Scheiner, S.M., Gurevitch, J. (Eds.), Design and Analysis of Ecological Experiments. Oxford University Press, New York, pp. 432.

Kruse, P.D., Toft, S., Sunderland, K.D., 2008. Temperature and prey capture: opposite relationships in two predator taxa. Ecol. Entomol. 33, 305-312.

Mercado, V.E.T., Maza, M.E.Z., Pantoja, A.M.S., 2017. Functional response of Cydnodromus picanus (Acari: Phytoseiidae) on two-spotted spider mite, Tetranychus urticae (Acari: Tetranychidae). Acta Agronómica 66 (2), 275-281.

Nentwig, W., Blick, T., Gloor, D., Hänggi, A., Kropf, C., 2018. Spiders of Europe. Version 02.2018. Available at: http://www.araneae.unibe.ch (accessed: 28.02.2018).

Pasandideh, A., Talebi, A.A., Hajiqanbar, H., Tazerouni, Z., 2015. Host stage preference and age-specific functional response on Praon volucre (Hymenoptera: Braconidae, Aphidiinae) a parasitoid of Acyrthosiphon pisum (Hemiptera: Aphididae). J. Crop Prot. 4 (4), 563-575.

Perkins, M.J., Inger, R., Bearhop, S., Sanders, D., 2018. Multichannel feeding by spider functional groups is driven by feeding strategies and resource availability. Oikos 127 (1), 23-33.

Pritchard, D. 2017. Frair: tools for functional response analysis. R package version 0.5 . 100. Available at: https://CRAN.R-project.org/package $=$ frair (accessed: 15.09 2017).

Queiroz, O.S., Ramos, R.S., Gontijo, L.M., Picanço, M.C., 2015. Functional response of three species of predatory pirate bugs attacking eggs of Tuta absoluta (Lepidoptera: Gelechiidae). Environ. Entomol. 44 (2), 246-251.

R Core Team. (2016). R: a Language and Environment for Statistical Computing. R Foundation for Statistical Computing, Vienna, Austria. Available at: http://www.Rproject.org (accessed: 21.09.2017).

Real, L.A., 1977. The kinetics of functional response. Am. Nat. 111, 289-300.

Réjou-Méchain, M., Tanguy, A., Piponiot, C., Chave, J., Hérault, B., 2017. BIOMASS: an R package for estimating above-ground biomass and its uncertainty in tropical forests. Methods Ecol. Evol. 8, 1163-1167.

Rogers, D., 1972. Random search and insect population models. J. Anim. Ecol. 41, 369-383.

Royama, T., 1971. A comparative study of models for predation and parasitism. Res.
Popul. Ecol. 13, 1-91.

Scharf, I., Ovadia, O., Bouskila, A., 2008. Prey encounter rate by predators: discussing the realism of grid-based models and how to model the predator's foraging mode: a reply to Avgar et al. Am. Nat. 172 (4), 596-598.

Schmalhofer, V.R., Casey, T.M., 1999. Crab spider hunting performance is temperature insensitive. Ecol. Entomol. 24, 345-353.

Shimazaki, A., Miyashita, T., 2005. Variable dependence on detrital and grazing food webs by generalist predators: aerial insects and web spiders. Ecography 28, 485-494.

Settle, W.H., Ariawan, H., Astuti, E.T., Cahyana, W., Hakim, A.L., Hindayana, D., Lestari., A.S., 1996. Managing tropical rice pests through conservation of generalist natural enemies and alternative prey. Ecology 77 (7), 1975-1988.

Smout, S., Asseburg, C., Matthiopoulos, J., Fernández, C., Redpath, S., Thirgood, S., Harwood, J., 2010. The functional response of a generalist predator. PLoS One 5 (5), e10761. http://dx.doi.org/10.1371/journal.pone.0010761.

Solomon, M.E., 1949. The natural control of animal populations. J. Anim. Ecol. 18, 1-35.

Stellwagen, S.D., Opell, B.D., Short, K.G., 2014. Temperature mediates the effect of humidity on the viscoelasticity of glycoprotein glue within the droplets of an orbweaving spider's prey capture threads. J. Exp. Biol. 217, 1563-1569.

Tello Mercado, V.E., Zarzar Maza, M.E., Suarez Pantoja, A.M., 2017. Functional response of Cydnodromus picanus (Acari: Phytoseiidae) on two-spotted spider mite, Tetranychus urticae (Acari: Tetranychidae). Acta Agronómica 66 (2), 275-281.

Topping, C.J., Hansen, T.S., Jensen, T.S., Jepsen, J.U., Nikolajsen, F., Odderskær, P., 2003. ALMaSS, an agent-based model for animals in temperate European landscapes. Ecol. Model. 167 (1-2), 65-82.

Toscano, B.J., Griffen, B.D., 2014. Trait-mediated functional responses: predator behavioural type mediates prey consumption. J. Anim. Ecol. 83, 1469-1477.

Uetz, G.W., Halaj, J., Cady, A., 1999. Guild structure of spiders in mayor crops. J. Arachnol. 27, 270-280.

Vacante, V., 2000. Animali dannosi alle ortive da serra. In: Baccetti, B., Barbagallo, S., Süss, L., Tremblay, E. (Eds.), Manuale di Zoologia Agraria, Delfino, Rome, Italy. pp. 429-448.

Van Leeuwen, E., Jansen, V.A.A., Bright, P.W., 2007. How population dynamics shape the functional response in a one-predator-two-prey system. Ecology 88, 1571-1581.

Vollrath, F., Edmonds, D.T., 1989. Modulation of the mechanical properties of spider silk by coating with water. Nature 340, 305-307.

Vollrath, F., Downes, M., Krackow, S., 1997. Design Variability in web geometry of an Orb-weaving spider. Physiol. Behav. 62 (4), 735-743.

Vucic-Pestic, O., Rall, B.C., Kalinkat, G., Brose, U., 2010. Allometric functional response model: body masses constrain interaction strengths. J. Anim. Ecol. 79, 249-256.

Weldon, C.W., Boardman, L., Marlin, D., Terblanche, J.S., 2016. Physiological mechanisms of dehydration tolerance contribute to the invasion potential of Ceratitis capitata (Wiedemann) (Diptera: Tephritidae) relative to its less widely distributed congeners. Front. Zool. 31, 13-15.

Wise, D.H., Moldenhauer, D.M., Halaj, J., 2006. Using stable isotopes to reveal shifts in prey consumption by generalist predators. Ecol. Appl. 16 (3), 865-876.

Zuur, A., Ieno, E.N., Walker, N., Saveliev, A.A., Smith, G.M., 2009. Mixed Effects Models and Extensions in Ecology with R. Springer, New York, pp. 574.

\section{Further reading}

Windley, M.J., Herzig, V., Dziemborowicz, S.A., Hardy, M.C., King, G.F., Nicholson, G.M., 2012. Spider-venom peptides as bioinsecticides. Toxins 4, 191-227. 